\title{
How to Understand Limitations of the Right to Exit with Respect to Losses Associated with Health Worker Emigration: A Clarification
}

\author{
Yusuf Yuksekdag
}

Centre for Applied Ethics, Linköping University, Sweden; Institute of Philosophy, University of Bern, Switzerland, yusufyuksekdag@gmail.com

DOI: http://dx.doi.org/10.5324/eip.v12i2.2433

(cc) BY 1 This is an open access article distributed under the terms of the Creative Commons Attribution 4.0 International License, which permits unrestricted use, distribution, and reproduction in any medium, provided the original author and source are credited.

There is a recent interest in the ethics of high-skilled worker emigration through which the limitations of the right to exit are discussed. Insightful arguments have been made in favour of (or against) the emigration restrictions on skilled workers in order to tackle the deprivations in developing countries. However, there is still a need for clarification on how we can understand, discuss and implement limitations of a right from a normative perspective. Significantly, how we understand the limitation of a right might determine how we approach such limitations - both in terms of the process of assessing the limitations and in terms of their implications. In this paper, I identify two distinct ways to understand limitations of the right to exit with respect to losses associated with health worker emigration, while also pointing to their implications for restrictive policies: (i) as a matter of scope, and (ii) as a matter of weight or emergency, which requires a compensatory scheme for the individual right holders. While the emergency restrictions seem to be a point of convergence in the literature, what defines an emergency and the nature of the compensation still warrant exploration. To that end, I also discuss from a normative perspective what might constitute a public emergency that would give states a prima facie prerogative to regulate temporary limitations on the exercise of the right to exit. In addition, I briefly introduce the implications of emergency restrictions, with a particular focus on compensatory schemes for individual right holders.

Keywords: compensation, emergency, health worker emigration, right limitations, right to exit.

\section{Introduction}

It has been almost a decade since the skilled worker migration from developing contexts has attracted the interest of scholars in normative and political ethics (Hooper 2008; Brock 2009). One important question has been whether or not affluent states should manage, delay or restrict the immigration of skilled workers in order to 
tackle the effects of such migratory patterns on institutional capacity building in certain developing contexts and on the basic needs satisfaction of affected populations. However, especially with the recent contribution of Gillian Brock and Michael Blake (2015), there is an increasing interest in the ethics of high-skilled worker emigration, with a particular focus on health worker emigration and permissibility of the restrictions on the right to exit (Pevnick 2016; Oberman 2017).

In defence of the restrictions that states may place on emigration in order to tackle the losses associated with the mass exodus of human capital, some scholars, following Brock, provide reasons for why and when high-skilled labourers have certain responsibilities to help with the need satisfaction of deprived populations (Brock and Blake 2015; Hobden 2017; Yuksekdag 2018). In contrast, Blake (2017), for instance, argues that the right to exit has an important normative value in the liberal theory, in that the restrictions on the right to exit are not permissible - with the exception of some rare cases of emergencies such as pandemics or humanitarian crises.

Despite the insightful arguments in favour of or against the emigration restrictions on skilled workers (and health workers in particular) in order to tackle the deprivations in developing countries, there is still a need to specify how to understand, discuss and implement limitations of a right from a normative perspective. What does it mean for a right to have limitations? What kinds of situations would warrant limiting a right? Significantly, how we understand the limitation of a right might determine how we approach and implement such limitations - both in terms of the process of assessing when the limitations may be implemented, and in terms of their implications. This paper therefore aims to clarify the ways in which we can understand and discuss limitations of the right to exit, using health worker emigration as a case in point, and their implications for restrictive policies.

In this paper, after briefly introducing the background of the issue, I identify two distinct ways to understand limitations of the right to exit with respect to losses associated with health worker migration, while also pointing to their implications for restrictive policies: (i) as a matter of scope, and (ii) as a matter of weight or emergency which requires a compensatory scheme for the individual right holders. Then, taking the recent contribution of Brock and Blake as a backdrop, I discuss how limitations of the right to exit can be understood with respect to tackling basic health delivery deprivation due to the mass exodus of health workers in under-served contexts. While the emergency restrictions seem to be a point of convergence in the literature, defining what can be considered an emergency and its implications, such as the nature of the compensation, still warrant exploration. ${ }^{1}$ To that end, I discuss from a normative perspective what might constitute a public emergency that would give states a prima facie prerogative to temporarily restrict and regulate the emigration of its citizens. In addition, I briefly discuss the implications of emergency restrictions with a particular focus on the compensatory schemes for individual right holders.

The aim of this paper is not to take a stance on whether health worker migration is a valid case to limit medical professionals' exercise of their right to exit. This paper rather aims to clarify the ways in which we can understand limitations of the right as well as their implications.

\section{Background: Health worker emigration from under-served regions}

The mass exodus of skilled professionals from the under-served and resource-poor countries has the potential to diminish capacity building for institutions that provide 
the basic needs of citizens. Therefore, the effects of skilled labour emigration on developing countries continue to be a matter of concern, especially for the SubSaharan African (SSA) countries that have a critical shortage of skilled professionals, and health workers in particular.

Skilled workers migrate for several reasons. They may seek better pay or facilities, career advancement or simply sociopolitical stability. Migration can also engender positive results for populations in developing countries and for their developmental prospects (Clemens 2013). For example, migrant workers benefit from this scheme by providing their families with better education and health care, while the households in the source countries evidently enjoy the remittances. ${ }^{2}$ The destination countries, on the other hand, enlarge their expertise and meet the demands of their institutions, which sustain citizens' basic needs by accommodating migrant health workers either on a short- or long-term basis.

The skilled labour migration, however, does not simply refer to a movement or an economic gain and loss. It also raises concerns about the global imbalance of essential labour practices, access to basic needs and development goals in resource-poor regions of the world. One of the ways in which skilled migration poses vital concerns is the case of health worker emigration from the under-served regions such as the SSA region. Figures show that SSA countries carry one quarter of the world's disease burden and only three percent of health worker capital. One of the contributing factors to these critical shortages is the international movement of health workers from resource-poor and under-served regions such as the SSA to resource-rich countries. The International Organization for Migration's (IOM) 2010 report shows that around 28 percent of doctors and 11 percent of nurses originally from SSA countries are living and working in developed countries such as Australia, Belgium, Canada, France, Portugal, South Africa, Spain, the UK and the USA (IOM 2010: 120). The main concern, however, is the effect of their emigration on health outcomes in the SSA region. Since the veracity of the data coming from developing countries is questionable, it is difficult to substantiate a direct cause and effect, yet the correlation between the two variables is arguably a shared understanding (Young 2013; Buchan and others 2008). Along with insufficient medical resources and ineffective local distribution, lack of medical expertise is another factor to consider for health care delivery deficiencies in under-served regions like the Sub-Saharan African region (Brassington 2012: Brock 2012; Hooper 2008). Lack of medical expertise is argued to be a factor that threatens essential health care delivery to improve child health and to address HIV/AIDS, tuberculosis and malaria (Gupta and others 2011: 10; Dreesch 2005). For instance, countries with high child mortality rates are also likely to suffer most from a lack of qualified health workers (WHO 2013: 75).

That is why, especially recently, the ethical questions in the context of health worker emigration have attracted a great deal of attention (Brock and Blake 2015; Kollar 2017; Oberman 2017; Pevnick 2016). The questions cover a variety of aspects of the phenomenon, including, but not limited to, its wrongness, its effects on both sending and recruiting countries, and its implications for health workers' right to exit. The permissibility and legitimacy of emigration restrictions on the basis of the effects of health worker emigration, as well as the ethical implications of the restrictions, are also in the locus of Gillian Brock and Michael Blake's (2015) recent contribution, which has been a catalyst in the literature on ethics of emigration restrictions. Brock takes a pro-restriction stance and argues that citizens have certain duties to address 
the needs of their fellow nationals. Blake, on the other hand, argues that while it would be fair to expect the skilled workers to address the concerning detrimental effects of skilled worker emigration, the skilled workers are simply exercising their right to exit that is one of the basic liberties in the liberal theory, and the restrictions as such are not justifiable unless a certain form of a state of emergency exists (Brock \& Blake 2015; Blake 2017). This disparity resonates with the literature on the ethics of health worker emigration. While some argue for the importance of the right to exit, some claim that restrictions on the right to exit might be justifiable in consideration of individuals' exercise of the right to health care or on the basis of the needs and welfare of under-served populations (Moellendorf 2016; Kollar 2012; Pevnick 2016).

Despite the insightful arguments in favour of (or against) the emigration restrictions in order to tackle the effects of critical shortages of human capital in developing countries, there is still a need to specify how to understand and discuss limitations of the right to exit, and their implications, from a normative/ methodological perspective. For instance, while it is argued that many individuals' right to basic health care or access to basic needs might justify limitations on some individuals' right to exit, it is not always clear in the literature how the scholars treat the trade-off or limitation of rights itself. This paper, however, makes the claim that how we understand the limitation of the right to exit might determine how we approach such limitations, in terms of the process of assessing when such limits may be in place and also in terms of their implications, such as compensation for rightholders. In the next part, I highlight two ways to understand the limitations of a right: in terms of scope and in terms of weight.

\section{How to understand and discuss limitations of the right to exit: Scope and weight}

The right to exit is codified in international declarations and covenants, including the Universal Declarations of Human Rights (UDHR) and the International Covenant on Civil and Political Rights (ICCPR), which both recognize individuals' freedom to leave any country, including their own. Notably, the right to exit is argued to be a vital right, which especially protects individuals in authoritarian states and their exercise of an exit option. It is even considered a right that ensures a certain level of political accountability (Lenard 2015; Hobden 2017). The ICCPR does however permit states to place restrictions on the exercise of the right that are necessary to protect national security, public order, public health or morals or the rights and freedoms of others, and to be consistent with other rights recognised by the ICCPR (Council of Europe 2013). In other words, the ICCPR, while ratified by most countries in the world, subjects the right to exit to limitations on certain grounds, such as the concerns over public health. While the right to exit holds important interests and values, it is not necessarily treated as an absolute right and might be still subject to limitations on certain substantial grounds (Oberman 2017). It is, therefore, crucial to further specify and understand the different ways of discussing limitations and their implications. ${ }^{3}$

Basic liberties then might face limitations and be subject to trade-offs with conflicting liberties ${ }^{4}$ and competing moral considerations (Brock \& Blake 2015). An individual's freedom of expression, for instance, is considered limited to the extent that it does not entitle an individual to barge into someone else's private property to be heard; unless invited, no one is permitted to enter another person's residence. 
According to James Nickel's typology of trade-offs in human rights, there are two ways of accounting for why freedom of expression does not prevail here (Nickel 2005). The first account would hold that the right to freely express oneself, when properly considered, does not include within its scope a right to enter someone else's private property without permission to exercise free speech. This is treating or understanding the limitation as a matter of scope. The second account would hold that my right to free expression would normally allow me to enter another individual's residence, but in this rather particular case or emergency, that person's exercise of the right to private property outweighs my exercise of the right to free speech, since the former holds the higher priority in this particular case. This example illustrates an understanding of the limitation as a matter of weight ${ }^{5}$ (Nickel 2007: 43). The main difference is that, in the former example, the limitation is embedded in the scope of the right, while in the latter, it is rather a matter of weighing the norms pertinent to the specific case at hand (Edmundson 2004). ${ }^{6}$

\section{Understanding limitations of the right to exit on the basis of losses associated with health worker emigration}

The issue of limitations in terms of how they should be understood is generally undertheorized in the recent discussion on skilled worker emigration, and it warrants explication. For instance, in her defence of emigration restrictions, Gillian Brock hints at the possibility of treating and understanding the issue both as a matter of scope and as a matter of weight. As an example of permissible limitations, Brock first mentions the restrictions imposed upon the right to free speech that would prohibit an individual from entering someone else's residence only to be heard and to exercise her free speech. It is claimed that the exercise of a right often "bumps up against" many other liberties, claims and interests, as in the case of the right to free speech (Brock \& Blake 2015: 247). The expression of rights bumping up against moral considerations might be understood both as treating the conflict or trade-off as a matter of scope and treating it as a matter of weight. However, the limitation in question here seems to be treated as a matter of scope in that the right to free speech, within its scope, does not include a right to enter someone else's private space. Similarly, in the case of skilled worker emigration, Brock argues that she discusses the constraints built into rights triggered by other rights or by our duties, rather than arguing for when the rights can be suspended (Brock \& Blake 2015: 246). This is a certain particular understanding of right limitations as formulated by some in the literature (Collste 2011). Then, the duties of skilled individuals, if any, to help their compatriots access their rights or basic needs can here be referred to for the purpose of specifying one of the constraints, or the scope, of the right to exit. This would imply, for instance, that the right to exit of an individual, when properly considered, does not include a right to renounce one's duties of justice or urgent assistance owed to one's compatriots.

In addition, Brock refers to cases of emergency, such as the need to quarantine people as an urgent public health measure, in order to provide additional reasons for permissible emigration restrictions (Brock \& Blake 2015). An example would be cases where individuals are prevented from exiting an airport when the airport is considered ground zero for a possibly contagious but unrecognized disease. Notably, this line of reasoning is often referred to when explaining what is at stake in the case 
of critical health worker shortages in the under-served and developing contexts (Cole 2010; Sager 2014; Stanczyk 2012). Notice that here the issue can be described as a matter of weight: if and when justified, such temporary but urgent public health concerns would outweigh an individual's exercise of the right to exit for the specific case at hand. This understanding would hold that the right to exit would normally allow an individual to exercise a territorial exit from any territory including public spaces such as airports, but in this particular case, the population's interest in basic health delivery or individuals' right to health outweighs her right to exit, as the former holds the higher priority. ${ }^{?}$

Blake, on the other hand, asserts that health worker emigration from under-served countries is the only form of skilled labour migration, which instead represents a case of emergency where the basic health needs of the population might outweigh skilled workers' right to exit. Blake contends that 'ethical emergencies' are the only permissible claim to outweigh and infringe upon liberties, and he does not think the issue at hand should be understood as a matter of scope (Blake 2017). One might object, however, that emergency cases - where important moral considerations are at stake - can be, or even should be, considered and discussed as inherent exceptions of the concerning rights. Grégoire Webber (2009), for instance, in the context of constitutional rights, argues for a 'greater' specification to determine the limitations of rights. He problematizes how the language of rights sometimes avoids settling controversies in the case of constitutional rights, and he argues that the rights should be seen in conjunction with their limitations of scope. This can be done in the most comprehensive manner by taking into account a plethora of all the moral considerations, rather than discussing the limitations of rights afterwards (Webber 2009; Panaccio 2010). ${ }^{8}$ However, there are, arguably, two motivations why treating the issue of health worker emigration and diminishing basic health care delivery as a matter of scope to impose limits on the right exit is condemned, and why, following Blake, one might insist on taking the issue rather as a matter of 'ethical emergencies': a commitment to the priority of the right thesis, and the required justificatory and compensatory burden for emergency-based infringements.

\section{Taking health worker emigration from under-served countries (only) as an ethical emergency}

The question then is whether the issue at hand should rather be treated only as an emergency. Blake's motivation, for instance, for not treating health worker emigration and diminishing health delivery in the under-served regions as a matter of scope is his theoretical commitment to John Rawls's priority thesis which argues that the scope of liberties can only be specified in reference to other liberties (Rawls 1999). In this understanding, liberties prevail over the considerations of equal opportunities, fair reciprocity, economic or institutional development, and these considerations cannot specify the scope of a right. These moral considerations can only outweigh a liberty or a right in certain extraordinary circumstances such as epidemics, pandemics or a state of war. One possible objection to this line of reasoning is that the issue at hand can be understood as a matter of scope by underscoring a trade-off between two rights/liberties: the right to exit and the right to health (Moellendorf 2016). Notably, Blake disregards this strategy. ${ }^{9}$ A plausible explanation is that he takes the right to health as part of the principle of equal 
opportunity, which is second to the principle of basic liberties in the lexical priority order Rawls envisages in his theory of justice (Rawls 1999). However, Rawls also hints at a "basic needs principle" lexically prior to the basic liberties - by requiring that "the basic needs are met' first and foremost (Stanczyk 2016; Moellendorf 2016: 49; Kollar 2017). Then, it would be a plausible interpretation to ground 'a right to basic health care' in the lexically prior 'basic needs principle' and specify the scope of the right to exit respectively. However, this line of reasoning is beset by certain barriers. First, the trade-off between a right to exit and a right to basic health care seems to be pertinent only to certain under-served countries, which posits itself instead as a particular case of emergency. Therefore, it is appropriate to understand the trade-off between two rights as a matter of weight in the given emergency. Second, this objection overlooks the fact that the duty bearers of the right to basic health care are not individuals but rather the states - except for the duty of forbearance (Evans 2002). A claim that a specific individual has a duty to attend to the health needs of the population is not necessarily a moral consideration directly implied by the right to basic health care. ${ }^{10}$

The second motivation is, arguably, in part embedded in a practical concern: unlike what Webber assumes, not all moral dilemmas can be - nor even should be anticipated or resolved in advance, and the inclination to specify the scope of a right might result in certain harms and unfairness for the individual right holders by enabling a prerogative to limit the exercise of their rights without any compensation or due consideration (Edmundson 2004; Nickel 2007: 43). This is because specifying the scope of liberties is a part of liberalism that deals with specifying the inherent exceptions to a right; yet claiming that a liberty is outweighed by a moral consideration in a specific case of emergency might, on the contrary, be considered a significant deviation from the tenet of liberalism (Blake 2017). This differentiation is significant because, unlike the trade-offs in specifying the scope of a right, asserting that a right is overridden in the case of an emergency is still a 'wrong' imposed upon the person, even if it is a temporary and a permissible infringement (Edmundson 2004). Emergency restrictions would thus require compensation for the temporary delay and wrong imposed on an individual's exercise of the right concerned - yet the nature or extent of such compensation is not adequately discussed in the literature.

It is reasonable to be wary of treating the limitation concerned as a matter of scope, because doing so might otherwise create a restrictive prerogative for developing states: if the restriction is a matter of scope, it does not necessitate compensation as it is simply what the scope of the right commands (Oberdiek 2008: 143). Additionally, restrictive schemes might be exploited by states (Pevnick 2016). Relieving the issue of health worker emigration from under-served regions by arguing for an inherent exception in the right to exit might also imply that the right in question does not hold much significance, and thus there would be no reason to problematize the treatment of the individual whose right was overridden (Nickel 2007: 43). On the contrary, emergency-based restrictions would require quite a justificatory consideration and burden on the states. This is not to say that this approach is not feasible, yet its challenges on the practical level should be recognized. ${ }^{11}$

Points of view on emergency restrictions in the literature seem to assert that states have a prima facie prerogative to regulate the emigration of its citizens in acute deprivations or catastrophes. These situations can be exemplified by the critical shortages of health workers in under-served and resource-poor regions. Understanding the concerned limitation as a matter of public emergency arguably 
also captures the very nature of the comparison between an individual's right to exit and many individuals' right to basic health care or access to basic needs in the given context. ${ }^{12}$ But this prerogative would be conditional upon respecting the right by compensating the individuals for the temporary delay - when the restrictions are enacted on an emergency justification.

\section{How to understand a (public) emergency and its implications}

While the permissibility of emergency restrictions on emigration seem to be a point of convergence in the normative literature in general, defining an emergency with reference to what kind of stakes should be involved, as well as the nature of the compensation, is not given sufficient attention. ${ }^{13}$ In order to be able to discuss time, place and extent/manner of emergency-based restrictions - especially when it comes to public emergencies like public health crises - there is merit in first understanding what constitutes and establish an emergency from a normative perspective. A normative perspective refers to what kind of moral framework/approach is to be utilized as a reference point in considering a situation a public emergency. Notably, while the notion of supreme emergency, for instance, is heavily used in the discussions on just war and justifiable conducts in war, the idea of emergency as such is largely confined to overwhelmingly horrifying situations and matters of collective survival (Sandin 2009). On the other hand, while public health ethics literature accommodates a great deal of ethical debate on public emergency preparedness, resource allocation and rationing, in addition to offering practical guidelines on viability and transparency of the measures, a more general reference point to discuss what constitutes an emergency from a normative point of view is still open to exploration (Jennings and others 2016; Wynia 2007). This would provide a fruitful starting point to discuss the possibly countervailing moral considerations, if weighty enough, that could outweigh interests supporting a particular exercise of the right to exit in the given situation (Nickel 2005; Edmundson 2004: 149).

Next, I introduce two different frameworks to discuss and constitute why a given situation should be considered an emergency, for instance, in the case of public health crises such as the critical shortages of health workers: a human rights framework and a basic needs framework. Lastly, I briefly discuss the implications for restrictive policies with a focus on what kind of compensatory schemes can be offered as a residual consideration for the infringement of the right to exit.

\section{What constitutes a public emergency from a normative perspective?}

An emergency can be defined as a situation in which there is a risk of considerable harm, and which requires an urgent response if the concerning harm is to be prevented or minimized (Sorell 2002: 22; Rubenstein 2007). An important categorization concerning the type of emergencies is the distinction between private/individual and public/systemic emergencies. Public emergencies can be described as emergencies that threaten the interests of a large group of people or a territory or the whole state, while individual emergencies are ones that individuals face in their own limited capacity - unlike an epidemic, drought or large scale environmental crisis $^{14}$ (Sorell 2002: 22). A public emergency, then, represents a state in which a territorial or a collective interest in certain essential needs, goods, values 
or rights are at stake rather than an individual's or a few individuals' interests (Rubenstein 2007). Further, it is conventionally considered a state's responsibility to tackle a public emergency by instituting the relevant measures (Sorrell 2002; Tanguay-Renaud 2009). The reason for the focus on the state and its officials as the responsible party to address the given emergency can be explained by the assumption that state officials are in the best position to tackle the emergency, given their de jure or de facto authority over the territory and their ease of access to and use of resources (Tanguay-Renaud 2009: 35).

But as a long-lasting phenomenon, is the critical shortage of health workers in the SSA really a case of public emergency? Eszter Kollar (2017) argues that health worker emigration from under-served countries might be better represented as a chronic or disastrous situation, rather than as an emergency, given that the nature of the threat is not imminent but already occurring. However, there might not be a moral difference between a situation where the harm or evil has already been at play and a situation that poses an imminent risk of harm. Rather, what is worrisome and what constitutes an emergency are better understood in connection with the kinds of significant interests or values that are at stake. Blake also disputes this conceptually grounded objection and claims that a public emergency should rather be understood in terms of the potentially very worrisome stakes involved in a given situation (Blake 2017: 566).

What then are the stakes that might establish the given issue as an emergency? According to Blake, human rights might be one of the reference points (Blake 2017). In addition to a human rights framework, the protection of subsistence or basic needs, or the survival of the political regime are examples of potential normative frameworks that would constitute a public emergency (Moellendorf 2016; Rubenstein 2007). The next two sections discuss the human rights approach to public emergencies and its challenges, and introduce a basic needs approach to public emergencies. This will be followed by a brief introduction to some of the implications of emergency restrictions with a particular focus on potential compensatory schemes.

\section{Human rights as the constitutive normative idea to understand what establishes a public emergency}

Human rights as the locus for understanding what establishes a public emergency is one approach that might be motivated by the normative and justificatory power of human rights and human rights discourse (Griffin 2008: 19). This approach would regard a public emergency as a situation where an entity - usually the state - is anticipating or experiencing a shortfall of the goods or resources necessary to protect human rights. Then, in the context of health worker emigration from resource-poor and under-served regions, a public emergency can be understood as a situation when the state and public officials are in a state of shortfall of the necessary goods and human capital to provide protections for the right to security, the right to health, and the right to subsistence. The next step would be to discuss the time, extent and degree of the public emergency for the population, which would be balanced and weighed against the interests of a health worker's exercise of the right to exit in the particular case where the right is infringed to address the emergency.

However, a human rights understanding of public emergencies has certain challenges. The first challenge is the inflation-deflation controversy in the human 
rights theory (Ignatieff 2002: 90). While there is a tendency to consider almost every moral consideration a potential matter of human rights, some relatively more confined frameworks aim at delimiting the scope of human rights to prevent an inflation of what is considered a human right (Tasioulas 2014; Griffin 2008). A human rights approach therefore carries the risk of confining the limits of a public emergency to a very narrow understanding of what is at stake, while it also has the potential to have a very inflated understanding of what would constitute a public emergency.

The second challenge involves the potential implications of the much-debated universalism versus contextualism discussion in human rights literature on understanding what would constitute a public emergency. The normative and political significance of a human rights approach is mainly located in its universalistic claim that certain rights should be conferred upon all individuals in the world, simply on the basis of being a fellow human being. Regardless, human rights, as understood within the normative literature, does mainly belong to a liberal paradigm of rights that take the rights of individuals as protections of their individual capacities without any reference to the sociocultural context the individual is encumbered with (Farrelly 2004: 99-101). The challenge of contextualism is that the universal human rights regime might neglect certain important social goods or needs that are only meaningful in the given context. If so, this would challenge the project of shared moral ideals and a universal understanding of human rights. For instance, while in certain contexts the autonomy of individuals is asserted as a fundamental value to uphold, individual autonomy might be valued less in some societies if it is considered detrimental to solidarity and other forms of social goods and values (Griffin 2015: 558).

Another related concern is at the discourse level - the imperialistic discourses embedded in or facilitated by the human rights accounts. This is because certain accounts of human rights have repeatedly been criticized of sustaining a sort of "rights imperialism":

Accounts of human rights have often been accused of rights imperialism: the discourse of human rights, it is said, is a peculiarly Western one which has been imposed on the rest of the world either actively against its wishes, or at the least without pause for any form of consultation. For Costas Douzinas, global human rights are part of the project of cosmopolitanism, a project which began with emancipatory intent but inevitably slipped into imperialism from the very beginning (Hann 2016: 161).

A potential worry, then, is that a state which is labelled as not respecting the human rights of its citizens from a Western-liberal perspective - despite its potential good faith to provide for the basic needs of its citizens - might not be considered a legitimate actor, in the international arena, to impose restrictions on the rights of its citizens on the basis of an emergency. A normative understanding of what constitutes a public emergency on the basis of human rights protections might therefore also carry, at the discourse level, a similar threat of imperialism and intervention towards non-Western states.

One might claim that a needs-based perspective of human rights or a contractualist political conception of human rights might overcome some of the challenges of contextualism. Human rights would then be confined to certain basic needs that are assumed to be meaningful to every individual regardless of residence 
and sociocultural background. However, two possible objections may arise to this counterargument. The first is that the moral significance attributed to the human rights approach to understand what an emergency is seems to become obsolete if what constitutes a public emergency in the end boils down to protecting needs. If the challenge of contextualism is countervailed by providing an index of basic needs or basic capabilities as a reference point to understand what an emergency is, this makes it less compelling to sustain human rights as the reference point. Second, this would be confining and establishing a very narrow understanding of human rights, which would endure criticism from the advocates of agency-based or political accounts of human rights (Griffin 2008; Beitz 2009).

\section{Using a basic needs framework to understand what establishes a public emergency}

Another approach would be to understand public emergencies as referring to basic needs of the population - parallel to what is described above as Rawls's 'basic needs principle'. The justificatory power of understanding public emergencies on the basis of basic needs would then be located in the idea that certain basic needs or the capacity to provide basic needs should be enacted first and foremost in any given context (Rawls 1999). In this understanding, a public emergency would be a situation where, for instance, an entity - usually the state - is anticipating or experiencing a shortfall of the goods or resources or institutional capacity necessary to protect the basic needs of its citizens.

The needs approach, on the other hand, also posits the controversy of inflationdeflation. Basic needs can be conceptualized as the goods and resources that are necessary to have a 'decent' life. They can be perceived as volitional to some extent, although it is also compelling to confine our understanding of basic needs to the level of mere subsistence (Brock 2009). A very confined conception of the basic needs approach might refer only to "very basic needs" which are the needs "vitally necessary for physical functioning" that are "non-volitional" and "immutable" (Brock 1999: 175). While the conceptualization of "very basic needs" is still open to interpretation, some non-contingent needs, such as food, clean water, clean air, basic health care, and basic shelter, can be exemplified. The normativity of such non-contingent and non-volitional very basic needs would then arise from their sheer necessity and the incapability of individuals to do without them to continue living (Schuppert 2013: 28). Then an emergency-based justification of restrictions would need to claim that when the state is unable to provide the very basic needs of its citizens, restrictions on the rights, such as the right to exit, are necessary and viable temporarily for the state to retain its capacity to provide the relevant resources.

Another potential objection to a basic needs framework is the exclusion of liberties from the approach - given that the right infringements of certain individuals would be enacted with no reference to the capacity to protect their liberties in the future, but rather to the capacity to provide basic needs. Nevertheless, the metric of basic needs might provide another insightful framework through which a given situation could be considered a public emergency.

In the case of critical health worker shortages in resource-poor countries, an emergency justification of restrictions on the right to exit would stem from a situation when the state is unable to provide the necessary resources and health capital for very 
basic health care delivery. Care is arguably a substantial aspect of basic health care delivery, and a basic health care provision requires an adequate number of physicians, nurses and other care providers (Eyal and Hurst, 2008: 180). The critical shortage of health workers in the SSA region, for instance, is one of the prominent factors in the populations being extremely vulnerable to ill-health and mortality from enduring epidemics of HIV/AIDS, malaria and tuberculosis - along with poverty, lack of medical equipment and health illiteracy (McCoy, McPake \& Mwapasa 2008). In particular, HIV/AIDS prevalence in countries such as Zimbabwe requires extensive and continuous care to manage the epidemic and the treatments to sustain adherence and prevent viral resistance, and the low number of health workers is deemed a very significant challenge for health care institutions in meeting the basic needs of the populations (Price \& Binagwaho 2010).

\section{Implications of Emergency Restrictions and Compensatory Schemes for Temporary Infringement of the Right to Exit}

Note here that conceptualizing the critical shortages of health workers in the SSA as a public emergency on the basis of basic needs, for instance, is not to directly justify temporary emigration restrictions on health workers. Such restrictive measures would require discussing the extent and degree of a basic-needs emergency in order to weigh the situation against the interests of the concerning health workers' exercise of the right to exit. The physical, social, occupational and institutional hardships that some under-served contexts might bring about for individual health workers warrant due consideration of the emergency restrictions (Chikanda 2011).

First, restricting individual rights on the basis of public emergencies has some much-debated implications in regard to concerns over viability, transparency and accountability of the restrictive measures (Wynia 2007). Affected states must maintain a certain degree of accountability and transparency while implementing emergency restrictions. Confining the emergency justification of restrictions to a certain framework, such as basic needs, might also be appealing given the potential ambivalence about the many actual state of emergencies, and why they are instituted and sustained.

Second, the legitimacy of the states implementing emergency restrictions, even if on substantial grounds, should be opened to question - especially considering contexts that harbour elements of oppression or right violations. Since scepticism towards states that might exploit restrictive measures is one of the motivations for treating the concerned limitations as a matter of emergency, such concerns about the legitimacy of the restricting party would still hold for emergency restrictions. According to Brock (2015), for instance, showing good-faith efforts to respect human rights would be one way of measuring the legitimacy of states that plan to implement such restrictions. Following Brock, it can be even argued that states implementing restrictions on the basis of emergencies should, at the very least, show good faith efforts to uphold a certain level of viability, transparency and accountability for the restrictions to be ethically permissible.

Notably, very little attention is given to compensatory schemes as one of the implications of emergency restrictions. Arguably, implementing certain forms of compensatory schemes would indicate a state's good-faith efforts to uphold a certain standard of legitimacy. However, the nature of the compensation owed to an 
individual whose exercise of the right is infringed warrants elaboration. Blake implies a monetary compensation for right infringements, and he finds it very demanding for resource-poor countries to compensate a temporary infringement of a health worker's exercise of the right to exit (Brock \& Blake 2015). Such monetary and demanding compensations are generally ruled, in the case of rights violations, within the context of constitutional and international courts. It might, however, be considered counterintuitive to assert that compensation owed in the case of a rights violation should be the same as that of a permissible infringement of a right, such as in a public emergency. This depends on whether the infringement itself should be problematized as the reason behind the compensation or if what is being infringed should rather guide this discussion. It can be argued that compensating simply because someone's right is infringed should not be the case if the infringement is a justifiable and permissible one, and a formal apology or expression of regret would be adequate compensation assuming no other harm or deprivation is involved (Wigley 2009).

Nevertheless, the role and nature of compensation in the libertarian theory, for instance, seems open to interpretation (Torpman 2016: 27). Such a compensation, or residual consideration, might take a variety of forms, such as an apology, recognition, or monetary compensation (Edmundson 2004: 149). In the case of a temporary infringement of the right to exit, while the extent of the infringement is the most important factor to consider, two different compensatory schemes can be offered that are not necessarily of a demanding nature for resource-poor countries: recognition and honour schemes, and schemes that facilitate the return of what is infringed/taken.

The first compensatory scheme might take the form of recognizing the infringement and honouring the infringed party. This scheme would aim to go beyond a public apology and additionally compensate the infringed party with a public recognition of the infringement. The individual could be honoured with a certain acclaimed professional status, for example. It is problematic to associate goods and values, which also have certain social meanings and attachments, with goods and values of monetary nature only, and compensation of this nature warrants some consideration at the very least.

The compensation scheme might also aim to restore what has been infringed or taken. While this is hard to measure, the reasons behind why the infringed right is valued could serve as a locus to discuss the metric of the compensation. For instance, according to Oberman (2017), the right to exit should be argued to protect individuals' interest in pursuing a full range of life options. In a particular case of emergency, if restrictive measures were to force a health worker to postpone (and lose the opportunity of) pursuing an internationally renowned career for a few years, the compensation then could take the form of facilitating certain means that encourage or even support the health worker to continue pursuing her career goals. These measures and compensation schemes of a monetary nature nonetheless are not mutually exclusive.

\section{Conclusion}

In this paper, I highlighted two distinct ways to understand and treat the limitations of the right to exit: as a matter of scope, and as a matter of weight or emergency which requires a compensatory scheme for the individual right holders. I applied these two understandings to discuss how to argue for restrictions of the right on the basis of 
losses associated with health worker emigration in developing countries - without taking a stance on whether the emigration restrictions are justifiable on the basis of health worker emigration from under-served regions.

The distinction laid out here contributes to the ethics of health worker emigration with two important points. The first is that there might be some pitfalls from an inclination to settle all limitations by specifying the scope of a right, as in the case of health worker emigration from under-served countries. It is reasonable to be wary of taking for granted that the right to exit have inherent limitations. Otherwise, this might lead to a harm or unfairness by not giving due consideration to the importance of the right and by not compensating the health worker whose exercise of the right to exit is infringed and delayed. The second point is that, while emergency restrictions are a point of convergence in the literature, what is considered an emergency and the nature of the compensation are open to question. To that end, I introduced the human rights framework and the basic needs framework as two different approaches to discuss and constitute why a given situation should be considered an emergency in the case of public health crises, via the example of critical health worker shortages. Finally, I briefly discussed what kinds of implications should be given consideration, with a particular focus on compensatory schemes for infringing the right to exit that warrant further research and reflection.

\section{Notes}

${ }^{1}$ While there is also a question of compensation to be demanded from the recruiting states, what is meant here by compensation is the compensation that might be owed to individuals whose exercise of the right is restricted.

${ }^{2}$ Although the data is a major issue, labour migration engenders redistribution of $\$ 430$ billion globally, two thirds of which go to developing countries, according to World Bank estimations. However, it should be noted that the potential of remittances is much debated. See: Haas, H. D. (2006). Migration, Remittances and Regional Development in Southern Morocco. Geoforum 374: 565-580.

${ }^{3}$ This paper offers a normative discussion on rights and their limitations: while not necessarily assuming the mirroring view (of moral/legal rights), the discussion offered here has implications for the discussion of legal (human) rights and their limitations.

${ }^{4}$ This is not to deny the compossibility thesis or any other strand of it. The aim is to show how one might understand limitations as such.

${ }^{5}$ For the case at hand, it has been more conventional to understand the exemplary trade-off as a matter of scope (Nickel 2007; Edmundson 2004).

${ }^{6}$ William Edmundson uses the terms "redescription approach" and "threshold view" respectively to point to the same differentiation. Another influential philosopher, Leonard Wayne Sumner, also refers to a similar categorization by referring to the content of a right (what the right is to), and the strength of a right (its significance over other moral considerations) (Edmundson 2004: 148; Sumner 1987: 1-4).

${ }^{7}$ It should be noted that specifying a scope of a right or claiming that it is outweighed by another interest, liberty or claim is not a moral trump card to hold that any form of restrictive policy is permissible in any context. Brock provides a legitimacy constraint for emigration restrictions on brain drain grounds to be justifiable. The 
state that institutes the coercive measures should hold a certain legitimacy measured by the respect for human rights, good-faith efforts such as providing an adequate amount and a diversity of public goods, operating on an impartial rule of law, and exercising a fair taxation and expenditure system (Brock \& Blake 2015).

${ }^{8}$ This way, Webber also aims at overcoming what he considers a moral loss of rights by making rights absolute and resistant to controversies. Notably, rights are not considered absolute in terms of their scope, but absolute in terms of the correlating duties once the scope is already bounded and specified (Panaccio 2010).

${ }^{9}$ Notably, there are accounts that argue for taking 'right to health care' as a basic liberty within a Rawlsian framework. See: Green, R. M. (1983). The Priority of Health Care. Journal of Medicine and Philosophy 8(4): 373-380.

${ }^{10} \mathrm{I}$ think this line of reasoning is, despite its challenges, valid and worth exploring by responding to the barriers.

${ }^{11}$ Significantly, rights such as the right to exit might also protect or promote the exercise of some other basic rights, such as the right to freedom of expression or freedom of association. This is referred to as fecundity of a right (Nickel 2005).

12 Notably, the way this type of comparison/limitation affects the way the balancing/trade-off at hand is done (in comparison to other types of comparisons, for instance) is still open to discussion and such a debate is essential to a more comprehensive account of right limitations.

${ }^{13}$ Kieran Oberman (2017), for instance, provides a detailed list of criteria to fulfil for emergency restrictions to be feasible, viable, proportionate, and legitimate - yet understanding what constitutes an emergency situation is of significance as a starting point to discuss issues and criteria such as proportionality.

${ }^{14}$ Such as the cases in which an individual's survival is only achievable if one infringes on another person's private property, as in the case of breaking into someone else's car to rush someone to a hospital.

\section{References}

Beitz, C. (2009). The Idea of Human Rights. Oxford: Oxford University Press. https://doi.org/10.1093/acprof:oso/9780199572458.001.0001

Blake, M. (2017). On emergencies and emigration: how (not) to justify compulsory medical service. Journal of medical ethics, 43(8), 566-567. https://doi.org/10.1136/ medethics-2016-103493

Brassington, I. (2012). What's Wrong with the Brain Drain? Developing World Bioethics, 12(3): 113-120. https://doi.org/10.1111/j.1471-8847.2011.00300.x

Brock, G. (1999). Morally Important Needs. Philosophia, 16(1-2): 165-178. https://doi.org/10.1007/BF02380064

Brock, G. (2009). Global Justice: A Cosmopolitan Account. Oxford: Oxford University Press. https://doi.org/10.1093/acprof:oso/9780199230938.001.0001

Brock, G. (2012). Is active recruitment of health workers really not guilty of enabling harm or facilitating wrongdoing? Journal of Medical Ethics. http://dx.doi.org/10.1136/medethics-2012-101136.

Brock G., Blake, M. (2015). Debating Brain Drain: May Governments Restrict Emigration? New York: Oxford University Press. 
Buchan, J., McPake, B., Mensah, K., Rae, G. (2008). Does a code make a difference assessing the English code of practice on international recruitment. Human Resources for Health 7(33). http://dx.doi.org/10.1186/1478-4491-7-33.

Chikanda, A. (2011). The Changing Patterns of Physician Migration from Zimbabwe. Journal of International Migration, Health and Social Care, 7(2): 77-92.

Clemens, M. (2013). Clemens, M. A. (2013). What do we know about skilled migration and development? MPI Policy Brief No. 3. Migration Policy Institute, Washington, DC.

Cole, P. (2010). The Right to Leave versus a Duty to Remain: Health-Care Workers and the 'Brain Drain'. In The International Migration of Health Workers: Ethics, Rights and Justice, ed. Rebecca S. Shah, 118-129. Basingstoke Hampshire: Palgrave Macmillan. https://doi.org/10.1057/9780230307292_8

Collste, G. (2011). Specifying Rights: The Case of TRIPS. Public Health Ethics 4(1): 63-69. https://doi.org/10.1093/phe/phr004

Council of Europe. (2013). The Right to Leave a Country. Retrieved November 11, 2016, from http://www.coe.int/t/commissioner/source/prems/prems150813 GBR_1700_TheRightToLeaveACountry_web.pdf.

Dreesch, N., Dolea, C., Dal Poz, M. R., Goubarev, A., Adams, O., Aregawi, M., Bergstrom, K., Fogstaad, H., Sheratt, D., Linkins, J., Scherpbier, R., Youssef-Fox, M. (2005). An approach to estimating human resource requirements to achieve the Millennium Development Goals. Health Policy Plan, 20(5): 267-276. https://doi.org/10.1093/heapol/czi036

Edmundson, W. A. (2004). An introduction to rights. Cambridge: Cambridge University Press. https://doi.org/10.1017/CBO9780511610936

Evans T. (2002). A human right to health? Third World Quarterly, 23(2): 197-215. https://doi.org/10.1080/01436590220126595

Farrelly, C. (2004). Introduction to Contemporary Political Theory. London: Sage Publications.

Green, R. M. (1983). The Priority of Health Care. Journal of Medicine and Philosophy, 8(4): 373-380. https://doi.org/10.1093/jmp/8.4.373

Griffin, J. (2008). On Human Rights. Oxford: Oxford University Press. https://doi.org/ 10.1093/acprof:oso/9780199238781.001.0001

Griffin, J. (2015). The Relativity and Ethnocentricity of Human Rights. In Cruft, R., Liao, S. M., Renzo, M. (Eds.), Philosophical Foundations of Human Rights (pp. 555569). Oxford: Oxford University Press. https://doi.org/10.1093/acprof:oso/ 9780199688623.003.0032

Gupta, N., Maliqi, B., França, A., Nyonator, F., Pate, M. A., Sanders, D., Belhadj, H., Daelmans, B. (2011). Human resources for maternal, new-born and child health: From measurement and planning to performance for improved health outcomes. Human Resources Health, 9(16). http://dx.doi.org/10.1186/1478-4491-9-16.

Haas, H. D. (2006). Migration, Remittances and Regional Development in Southern Morocco. Geoforum, 37(4): 565-580. https://doi.org/10.1016/j.geoforum.2005.11.007

Hann, M. (2016). Egalitarian Rights Recognition: A Political Theory of Human Rights. London: Palgrave Macmillan. https://doi.org/10.1057/978-1-137-59597-3

Hobden, C. (2017). Taking up the slack: The duties of source state citizens in the brain drain crisis. South African Journal of Philosophy, 36(1): 33-44. https://doi.org/ $10.1080 / 02580136.2016 .1261781$ 
Hooper, C. R. (2008). Adding Insult to Injury: The Healthcare Brain Drain. Journal of Medical Ethics, 34(9): 684-687. https://doi.org/10.1136/jme.2007.023143

Ignatieff, M. (2002). Human Rights as Politics and Idolatry. New Jersey: Princeton University Press.

IOM. (2010). World Migration Report 2010: The Future of Migration: Building Capacities for Change. Retrieved November 01, 2017, from https://publications.iom.int/system/files/pdf/wmr_2010_english.pdf.

Jennings, B., Arras, J. D., Barrett, D.H., Ellis B. A. (eds.) (2016). Emergency Ethics: Public Health Preparedness and Response. New York: Oxford University Press. https://doi.org/10.1093/med/9780190270742.001.0001

Kollar, E. (2012). Medical Migration between the Human Right to Health and Freedom of Movement. In Health Inequalities and Global Justice, eds. P.T. Lenard and C. Straehle, 230-246. Edinburgh: Edinburgh University Press.

Kollar, E. (2017). What is wrong with the emergency justification of compulsory medical service? Journal of Medical Ethics, 43: 560-561. https://doi.org/10.1136/ medethics-2015-103163

Lenard, P. T. (2015). Exit and the duty to admit. Ethics \& Global Politics, 8(1). https:// http://doi.org/10.3402/egp.v8.25975.

McCoy, D., McPake, B., Mwapasa, V. (2008). The double burden of human resource and HIV crises: a case study of Malawi. Human Resources for Health, 6(16). http://dx.doi.org/10.1186/1478-4491-6-16.

Moellendorf, D. (2016). Can a Liberal State Make Access to Medical Education Conditional on Public Service? Moral Philosophy and Politics, 3(1): 45-53. https://doi.org/10.1515/mopp-2015-0022

Nickel, J. W. (2005). Who Needs Freedom of Religion? University of Colorado Law Review, 10(24): 941-964.

Nickel, J. W. (2007). Making Sense of Human Rights. Oxford: Blackwell Publishing.

Oberdiek, J. (2008). Specifying Rights Out of Necessity. Oxford Journal of Legal Studies, 28: 127-146. https://doi.org/10.1093/ojls/gqm028

Oberman, K. (2017). Emigration in a Time of Cholera: Freedom, Brain Drain, and Human Rights. Law, Ethics and Philosophy, 4.

Panaccio, C. M. (2010). The Negotiable Constitution: On the Limitation of Rights. Cambridge University Press, 2009 (Grégoire Webber), International Journal of Constitutional Law, 8(4): 988-995. https://doi.org/10.1093/icon/mor012

Pevnick, R. (2016). Brain drain and compulsory service programs. Ethics \& Global Politics, 9. http://dx.doi.org/10.3402/egp.v9.33503.

Price, J., Binagwaho, A. (2010). From medical rationing to rationalizing the use of human resources for AIDS care and treatment in Africa: a case for task shifting. Developing World Bioethics, 10(2): 99-103. https://doi.org/10.1111/j.14718847.2010.00281.x

Rawls, J. (1999). A Theory of Justice. New York: Oxford University Press.

Rubenstein, J. (2007). Distribution and Emergency. Journal of Political Philosophy, 15: 296-320. https://doi.org/10.1111/j.1467-9760.2007.00279.x

Sager, A. (2014). Reframing the brain drain. Critical Review of International Social and Political Philosophy, 17(5): 560-579. https://doi.org/10.1080/13698230. 2014.919061

Sandin, P. (2009). Supreme Emergencies Without the Bad Guys. Philosophia, 37: 153167. https://doi.org/10.1007/s11406-008-9145-5 
Schuppert, F. (2013). Distinguishing basic needs and fundamental interests. Critical Review of International Social and Political Philosophy, 16(1): 24-44. https://doi.org/10.1080/13698230.2011.583532

Sorell, T. (2002). Morality and Emergency. Proceedings of the Aristotelian Society 103: 21-27. https://doi.org/10.1111/1467-9264.00126

Stanczyk, L. (2012). Productive Justice. Philosophy \& Public Affairs, 40(2): 144-164. https://doi.org/10.1111/j.1088-4963.2012.01212.x

Stanczyk, L. (2016). Managing skilled migration. Ethics \& Global Politics, 9(1). http://dx.doi.org/10.3402/egp.v9.33502.

Sumner, L. W. (1987). The Moral Foundation of Rights. Oxford; Clarendon Press, 1987.

Tanguay-Renaud, F. (2009). Making Sense of "Public" Emergencies. Philosophy of Management, 8: 31-53. https://doi.org/10.5840/pom20098215

Tasioulas, J. (2014). Taking Rights out of Human Rights. In Crisp, R. (Ed.), Griffin on Human Rights (pp. 9-45). Oxford: Oxford University Press. https://doi.org/ 10.1093/acprof:oso/9780199668731.003.0002

Torpman, O. (2016). Libertarianism and Climate Change (Doctoral dissertation, Malmö University). Malmö: University of Malmö, Stockholm University Press.

WHO. (2013). The World Health Report 2013: Research for Universal Health Coverage. Retrieved November 11, 2016, from http://www.who.int/whr/2013/ report/en/.

Wigley, S. (2009). Disappearing Without a Moral Thrace? Rights and Compensation During Times of Emergency. Law and Philosophy, 28(6): 617-649. https:/doi.org/ $10.1007 / \mathrm{s} 10982-009-9047-0$

Wynia, M. K. (2007). Ethics and Public Health Emergencies: Restrictions on Liberty. Bioethics, 7(2): 1-5. https://doi.org/10.1080/15265160701193559

Young, R. (2013). How effective is an ethical international recruitment policy? Reflections on a decade of experience in England. Health Policy, 111: 184-192. https://doi.org/10.1016/j.healthpol.2013.03.008

Yuksekdag, Y. (2018). Health Without Care? Vulnerability, Medical Brain Drain, and Health Worker Responsibilities in Underserved Contexts. Health Care Analysis, 26(1): 17-32. https://doi.org/10.1007/s10728-017-0342-x 